\title{
Learning from health care in other countries: the prospect of comparative research
}

\author{
van Teijlingen $\mathrm{E}^{1}$, Benoit $\mathrm{C}^{2}$, Bourgeault $\mathrm{I}^{3}$, DeVries $\mathrm{R}^{4}$, Sandall $\mathrm{J}^{5}$, Wrede $\mathrm{S}^{6}$ \\ ${ }^{2}$ Cecilia Benoit, PhD, University of Victoria, Canada \\ 3 Ivy Bourgeault, PhD, University of Ottawa, Canada \\ ${ }^{4}$ Raymond DeVries, PhD, University of Michigan USA \& Hogeschool Zuyd, Maastricht University, the Netherlands \\ ${ }^{5}$ Jane Sandall, PhD, King's College London, UK \\ ${ }^{6}$ Sirpa Wrede, PhD, University of Helsinki, Finland
}

\begin{abstract}
It is widely accepted that policy-makers (in Nepal and elsewhere) can learn valuable lessons from the way other countries run their health and social services. We highlight some of the specific contributions the discipline of sociology can make to cross-national comparative research in the public health field. Sociologists call attention to often unnoticed social and cultural factors that influence the way national reproductive health care systems are created and operated. In this paper we address questions such as: 'Why do these health services appear to be operating successfully in one country, but not another?'; 'What is it in one country that makes a particular public health intervention successful and how is the cultural context different in a neighbouring country?' The key examples in this paper focus on maternity care and sex education in the Netherlands and the UK, as examples to highlight the power of cross-national research. Our key messages are: a) Cross-national comparative research can help us to understand the design and running of health services in one country, say Nepal, by learning from a comparison with other countries, for example Sri Lanka or India. b) Cultural factors unique to a country affect the way that reproductive health care systems operate. c) Therefore, we need to understand why and how services work in a certain cultural context before we start trying to implement them in another cultural context.
\end{abstract}

Keywords: sociology; comparative studies; culture.

Submitted: 24 October 2014; Revised: 03 April 2015; Accepted: 28 June 2015

\section{Introduction}

Cross-national comparative research is a key tool in the social and health sciences, but such comparative research is not without its challenges $(1,2)$. When the organisation of health care is the topic at hand, such research is typically concerned with making comparisons across countries that are relatively similar in regard to their economy and policy (3). One area of keen interest in cross-national health care research has been the organisation of publicly-funded reproductive health care and, more particularly maternity care (4-6). A quick glance at the available evidence shows that the care system as well as the public/ private mix of "services" available to residents can vary significantly, even in countries that are relatively similar. Socio-economic factors, including income and wealth distribution, have been linked to variation in and between health care systems $(7,8)$, as has the impact of neoliberal market-mindedness on the medicalisation of maternity care (9). Cultural factors also play a major role in shaping the content and delivery of health services (10).

One of the earliest comparative studies of the organisation of health care found that the countries considered -- the United States (US), England, West Germany and
France -- had similar life expectancies and other broad health outcomes but had widely differing approaches to how health services are organized (11). We recognize the dangers of stereotyping; nevertheless we hold that comparative research on health care systems must take into account the socio-cultural context of different countries in order to explain such variation, often recognised as path dependency, meaning that past policies condition the policy alternatives available in future. The socio-cultural context and related path dependency shape the organisation and provision of health care through policies and institutions as dominant cultural ideas are embedded within them. These dominant ideas include, for example, percep-

\section{Correspondence:}

${ }^{1}$ Prof. Edwin van Teijlingen, PhD

Centre for Midwifery, Maternal \& Perinatal Health

Bournemouth House

19, Christchurch Road

Bournemouth University,

England, UK.

Tel: +44 (0)1202-961564

Email: vanteijlingen@bournemouth.ac.uk 
tions of the role of the state vis-à-vis the private market in the provision of health care: is health care seen as a public good or private commodity? Gender ideologies offer another example. Conceptions of gender shape the hierarchy of health professions and social roles in families. A focus on these core values highlights the way a given health system recognises (or not) the needs of a diverse population, including that society's most vulnerable members $(3,12)$. Yet it is also important to accommodate for the dynamics of change in health systems, considering, for instance, the globally salient neo-liberalization of maternity care systems in recent decades (13).

In this paper we shed light on variation in two key areas of reproductive health - sex education and maternity care - in two neighbouring European countries, England/UK and the Netherlands. We selected these two countries for the sake of brevity as we have research experience in various countries including Canada, the US and Finland. Thus these countries merely act as an example of the application of the comparative method, thus someone else might want to compare maternal health services in Nepal and Bhutan or compare reproductive health services in Nepal and Bangladesh. After outlining the advantages and disadvantages of comparative studies of health care systems, we show how these two national cases reflect different approaches to organising reproductive health care. Both countries have diverse populations and have developed a range of responses - that vary within and between countries - to reproductive health. We show how the health systems of the two countries, having evolved over a long period of time and reflecting their respective value systems, have their own distinctive approaches to reproductive health.

\section{Comparative Studies: Benefits \& Challenges? \\ Benefits}

One of the main benefits of comparative studies is that they challenge unquestioned assumptions through constant comparative means, as such they provide an alternative lens through which to view the organisation of health systems and their strategies for delivering services. We are all, to a greater or lesser degree, culturally-bound, and geographically embedded. Comparative studies that include different cultures or communities can help us to see common events from a new perspective that challenges common assumptions. A major advantage of cross-national comparative research is that it allows study of approaches that have not been considered in certain countries. The result is that problems can be looked at from a different angle, current practices can be questioned, and the effectiveness, efficiency and experiences of service users can be compared and contrasted (14).

Second, we can learn from each other's experiences and findings. Thus doctors and nurses working in reproductive health services with similar disadvantaged populations in, for example, inner-city London and Amsterdam, will likely develop slightly different outreach strategies. This may reflect the differences in what constitutes the most dis- advantaged groups in the two cities, but also expectation of services on offer by the intended target population locally. Moreover, identical solutions can have very different intended and unintended consequences in different countries or settings. Comparisons allow us to see how organisational constraints and different cultural ideas about what is desirable, good, and proper shape the delivery and utilization of health care.

Third, comparative studies can help us avoid making assumptions about any one particular cultural or ethnic minority group. These comparisons do not always have to be cross-national as highlighted in the following example on perception about teenagers from different ethnic minority groups in the UK. A qualitative study conducted with a relatively homogeneous sample of young Scottish people highlighted embarrassment as a key element in their discussions around sexual heath and sex education (15). A very similar finding has also been reported among teenagers in a multicultural area of London. Participants from a range of ethnic minority communities in the latter study "expressed feelings of embarrassment, discomfort and scepticism that parents might be able to understand them and their relationships" (16). Any one reading only the latter study with ethnic minorities could easily come to the conclusion that ethnic minority youths are too embarrassed to speak to their parents. But comparative research allows us to go beyond stereotypes and see the common ground (and the differences) between different groups of young people. Looking at both studies we learn that the embarrassment expressed by ethnic minority youths mirrors that of most people of that age group in the UK. Finally, the comparative method helps us to learn from each other in the process of doing research, challenging our ethnocentric view about what is "normal" or "abnormal" in other cultural contexts (17). The benefits gained from cross-national work include a deeper understanding of other cultures and of their research processes (18), as well as how to alter health care systems to better meet the needs of their diverse populations.

\section{Challenges}

This is not to say that comparative research is easily accomplished (19). A significant challenge of comparative studies concerns the way any social institution is bound to its socio-cultural context. As noted above, some have warned against trying to transfer ideas/solutions from one setting to another: the fact that something works well in one context does not guarantee that it will work elsewhere. For example, Benoit warns about the impossibility of transplanting the basic elements of the Canadian public health care system to the US because of its different core principles (20). In a similar manner, Mander questioned the feasibility of implementing aspects of the Dutch maternity care system elsewhere because its system was similarly created around country specific principles and practices (21). This, as we shall see, is relevant to reproductive health care when viewed more broadly.

\section{Comparative Case Studies of Reproductive Health Care}

Below we briefly introduce two examples of comparative 
Table 1: Selected reproductive health \& maternity care data*

\begin{tabular}{|c|c|c|}
\hline Characteristics & England \& Wales & The Netherlands \\
\hline Teenage (under 20s) conception rate per 1,000 & 61.7 & 14.3 (age 15-19) \\
\hline Teenage abortion rate per 1,000 & 42.6 & 9.1 (age 15-19) \\
\hline Total fertility rate (average number of children per woman) & $1.97(2008)$ & $1.77(2008)$ \\
\hline Home birth rate & $2.7 \%(2007)$ & $29 \%(2005-08)$ \\
\hline Caesarean Section rate & $24.6(2007-08)$ & $15.4(2007)$ \\
\hline \multicolumn{3}{|c|}{$\begin{array}{l}\text { * The following UK sources were used for the data in Table 1: ONS (Office for National Statistics) Table 4.1 Con- } \\
\text { ceptions: age of woman at conception, www.statistics.gov.uk/STATBASE/Expodata/Spreadsheets/D9558.xIs; ONS } \\
\text { (Office for National Statistics) Home births continue gradual increase Population Trends } 133 \text { - Autumn } 2008 \text { (25 } \\
\text { Sept.) www.statistics.gov.uk/pdfdir/poptrdhb0908.pdf; NHS Maternity Statistics, England 2008-09: Headline Tables; } \\
\text { and the following Dutch sources: CBS 'Bevallingen naar plek en thuisbevallingen naar opleidingsniveau, 1997-2008, } \\
\text { http://www.cbs.nI/NR/rdonlyres/E4C58356-27F3-4E20-B172-55D156AAAB83/0/2696T.x/s; CBS STATLine, http:// } \\
\text { www.statline.cbs.nl/StatWeb/publication/?VW=T\&DM=SLNL\&PA=37422ned\&D1=0,4-5,7,9,11,13,17,26,35,40- } \\
\text { 41\&D2=0,10,20,30,40,(I-4)-I\&HD=090218-0953\&HDR=G1\&STB=T; Stichting Perinatale Registratie Nederland } \\
\text { (2009) Perinatal Care in the Netherlands 2007, Utrecht: Stichting Perinatale Registratie Nederland Report available } \\
\text { from www.perinatreg.nl. }\end{array}$} \\
\hline
\end{tabular}

research, starting with sex education and followed by pregnancy and childbirth in England/UK and the Netherlands. Table 1 describes key differences in the reproductive health outcomes and methods of childbirth in our two countries of comparison at one point in time. As the data in Table 1 make clear, there are large differences between the two countries in terms of teenage pregnancies and abortions, and in the way babies are brought into the world. This raises an interesting question: "How is it that countries in Northwest Europe that are similar in so many respects (e.g. socio-economic development, proportion of public funds spend on health services, proportion of migrants in the populations) have such differences in reproductive health and health care?"

\section{I: Sex education}

The Netherlands is often praised as a country providing comprehensive and effective sex education for its young people (22-25). The international reputation of the Dutch is partly based on its comparatively low teenage pregnancy rates as well as very low abortion rates. England and Wales have much higher teenage pregnancy rates (63 per 1000 young women) when compared with 8.1 per 1000 young women (aged 15-19) in the Netherlands (26). The comparative low Dutch teenage conception and abortion rates hold up to comparison with other countries as well. Some years ago, Keys and colleagues compared the birth rate for the under $20 \mathrm{~s}$ in the Netherlands $(6.2 / 1,000)$ with that of the US $(52.2 / 1,000)$, arguing that in countries where "public health policies adopt a comprehensive approach, birth rates among the young tend to be lower" (27). Until recently, the Dutch teenage pregnancy and teenage abortion rates are amongst the lowest in the world; in contrast, England and Wales have one of the highest rates of teenage pregnancy rates in Western Europe (28-29). However, the latest data for England and Wales show that teenage (under 18s) conception rates are at their lowest since 1969 (30).
The low Dutch teenage pregnancy rates (Table 1) have been attributed to, amongst others: (a) the willingness of parents to discuss safe sex, birth control and related matters; (b) assertiveness training in relation to sex education in primary schools; and (c) widespread availability of reproductive healthcare (22). Sex education in Dutch schools is also less contentious than that in England and Wales. A recent systematic review (of English-language publications) on the topic of sex and relationship education revealed that important barriers to effective sex education persist: (a) resistance from schools; (b) teachers refusing to deliver (some) behavioural aspects of sex education to students, including proper use of condoms, especially in primary schools; and (c) attitudes of staffs delivering the interventions; conversely, involvement and approval of the community and parents are positive factors in improving behavioural intentions (31). Furthermore, this review indicated that the majority of interventions targeted young people who were already sexually active, despite the evidence that suggests starting sex education before young people become sexually active, may delay sexual debut (31). These facts suggesting that both sex education policy and practice are driven (or hindered) by cultural values, the consequences for young people's sexual and reproductive health are notable.

\section{II: Maternity care}

The Netherlands is known globally for its relatively high proportion of home births - compared other high-income countries, including England - and the high degree of professional independence community Dutch midwives enjoy. Key characteristics of the way the Dutch organise midwifery and maternity care include the: (1) role and position of midwives; (2) high proportion of home births; (3) support of obstetricians for a health system in which midwives do the risk selection; (4) availability of maternity home care assistants supporting midwives and women at home; and (5) long-term government support for home 
birth. Of course, several of these characteristics can be found in other countries, for example in Britain risk selection is a very much part a midwife's task, and there are a growing number of maternity assistants.

In order to better understand this Dutch/British difference in homebirth, pregnant women's experiences or the place of midwives in the maternity services, it is useful to lift one's gaze and consider the organization of maternity care practices in other countries. Important clues for explaining the differences we see here can be found in the book, Birth by Design (19). This edited volume collected cross-national comparisons of maternity care in a number of high-income, technologically-sophisticated countries, including Canada, the US, the UK and the Netherlands (19). Using a decentred approach that was sensitive to the cultural, socio-economic and organisational context of maternity care in different countries, the researchers discovered interesting and important cultural and structural variations in everything from the training of the providers of maternity care, to public policy, to the attitudes of women about desirable care (2).

\section{Comparative research as a method}

To explain our observed differences in reproductive care in two seemingly similar countries, we need to examine the underlying cultural values of each society. Cultural values are not fixed essences but symbolic boundaries that all of us invoke to order and make sense of our lives and of issues that provoke controversy in a community. When making health policy, governments are called on by social movement actors and members of the general public to make a stand on intervening (or avoiding intervention) in matters that are subject to value judgements and moral views.

In the Netherlands, the government has refrained from making policies that intervene in the sexuality of teenagers, instead seeking to minimise the negative consequences by offering sex education and making prevention accessible (21). Some outsiders praise and others condemn the liberal Dutch approach that is 'soft' on drugs, prostitution, home birth, sex education and euthanasia. Generally, the government has chosen approaches that limit valuebased interventions in matters that concern the realm of personal life, while promoting harm reduction to protect its citizens from negative consequences. Of course, giving women the right to opt for a home birth fits very well with this philosophy.

Public policy in the Netherlands is generally pragmatic. The Dutch style of policymaking has been described as "weigh up the problems and solutions and adapt" (22). This comes through in the aversion to using policy to take moralistic stances and in a willingness to experiment on a small-scale with new approaches to health and social policy, testing its efficacy and efficiency. Health policies in the UK have a more rational evidence-based approach, whereby largely independent organisations, such as NICE (National Institute for Health and Care Excellence), operate at a distant from government and thus help deal with politically unpopular rationing decisions (32).

\section{Summary \& Conclusion}

Comparative studies, especially when conducted using a decentred method (3), can help us to see the "oddness" of the ways our own society deals with core issues of human life such as reproductive health. The discipline of sociology augments comparative research by encouraging us to question the assumptions about our own ways of doing things by observing the "strange" ways of others. At the same time we should not forget that (a) significant variations exist within countries and between sub-regions; and (b) it is all too easy to fall into the trap of perpetuating cultural stereotypes. Our findings indicate that public health practitioners, health care professionals, health promoters and policy makers need to take more seriously the wider social and cultural context shaping the delivery of sex education and maternity services. It is clear that the design of reproductive health care and services varies widely between countries and clearly bears the marks of the society in which it is found. Of course, many of us are not just interested in studying differences in services and systems for its own sake, we want to show that one is more successful than another in, for example, reducing health inequities and increasing access to quality reproductive services. Thus we want to introduce what we have learnt in one country or system, not by simply copying what was done there, but by ensuring that what we introduce in another is culturally and socially appropriate.

Reproductive health is a matter that engages both individuals at the level of their personal lives and societal actors making policies about the different practices that intervene in the personal lives of the members of society. Sexual health and maternity care are contentious arenas of health intervention as they are surrounded with cultural and moral issues (or 'problems') this is something all societies must come to terms with and each society does this within its own national cultural context. We hope this paper will be of use to researchers in Nepal who are thinking about doing comparative research. For example, a Nepalese researcher might consider comparing condom distribution in India and Nepal. Our methodological reflections may help him or her to consider why the Indian solution distributing condoms may or may not work in Nepal.

Thus value-laden issues, for which there are different cultural approaches to care, have different outcomes - and indeed, may be completely contrary to what the policymakers are intending. Using a cross-national lens to examine reproductive health systems highlights not just what works best, but why some strategies of care are better suited to some cultures, regions or countries than others, and why some strategies are more difficult/easy to implement in some contexts than in others.

\section{References}

1. Corless IB, Nicholas PK, Nokes KM. Issues in cross-cultural qualityof-life research. J Nurs Scholarsh. 2001; 33(1): 15-20.

2. Voils, C.I., Maciejewski, M.L. Challenges and opportunities in comparative effectiveness research Comparative Effectiveness Research 2011:1 39-41

3. Wrede S, Benoit C, Bourgeault IL, van Teijlingen ER, Sandall J, De Vries R. Decentered Comparative Research: Context Sensitive Analysis 
of Health Care, Soc Sci Med 2006; 63: 2986-2997.

4. Christiaens W, Gouwy A. Bracke P. Does a referral from home to hospital affect satisfaction with childbirth? A cross-national comparison, BMC Health Serv Res 2007; 7:109. www.biomedcentral.com/1472 $6963 / 7 / 109$.

5. Benoit C, Heitlinger A. Women's health care work in comparative perspective. Soc Sci Med 1998; 47(8): 1101-1111.

6. Van Lerberghe W, Matthews Z, Achadi E, Ancona C, Campbell J, Channon A, de Bernis L, De Brouwere V, Fauveau V, Fogstad H, Koblinsky M, Liljestrand J, Mechbal A, Murray SF, Rathavay T, Rehr H, Richard $F$, ten Hoope-Bender P, Turkmani S. Country experience with strengthening of health systems and deployment of midwives in countries with high maternal mortality. Lancet 2014; 384: 1215-1225.

7. Whitehead M, Dahlgren G, Mclntyre D. Putting equity centre state. Int J Health Serv 2007; 37: 353-361.

8. Wilkinson RG. Unhealthy Societies. The Afflictions of Inequality. London: Routledge, 1996.

9. Benoit, C., Zadoroznyj, M., Hallgrimsdottir, H., Treloar, A., Taylor, K. (2010). Medical Dominance and Neoliberalisation in Maternal Care Provision: The Evidence from Canada and Australia. Soc Sci Med. 71, 475481.

10. DeVries R, Wrede S, Benoit C, van Teijlingen E. Making Maternity Care: The Consequences of Culture for Health Care Systems, pp. 209-23 in H.Vinken, J. Soeters, P Ester (eds). Comparing Cultures. Tilburg, the Netherlands, IRIC / Tilburg University, 2004

11. Payer L. Medicine \& Culture, London: Victor Gollancz Ltd, 1990.

12. DeVries R. A Pleasing Birth: Midwives and Maternity Care in the Netherlands. Philadelphia: Temple University Press, 2005.

13. Benoit C, Sandall J, Benoit C, Murray SF, van Teijlingen E, Wrede S, Declercq G. New directions in global policy: maternal health. In: E Kuhlmann, E., Bourgeault, I. (eds.) Palgrave International Handbook on Health Care Policy \& Governance, Houndmills: Palgrave Macmillan, 2015.

14. Collins CD, Green A, Hunter D. National Health Service reforms in the United Kingdom and learning from developing country experience. J Man Med 2000; 14: 87-99.

15. van Teijlingen E, Reid J, Shucksmith J, Harris F, Philip K, Imamura M, Tucker J, Penney G. Embarrassment as a key emotion in young people talking about sexual health, Sociol Res Online, 2007; 12 (2) www. socresonline.org.uk/12/2/van_teijlingen.html

16. Sinha S, Curtis K, Jayakoby A, Viner R, Roberts H. Family and Peer Networks in Intimate and Sexual Relationships Amongst Teenagers in a Multicultural Area of East London, Sociol Res Online 2006; 11(1) www. socresonline.org.uk/11/1/sinha.html.

17. Benoit, C. Wrede, S., Bourgeault, I, Sandall, J., DeVries, R., van Teijlingen E. (2005) Understanding the social organisation of maternity care systems: Midwifery as a Touchstone, Sociol Health Illness 2005; 27(6): 722-737.
18. Hantrais L Comparative Research Methods, Soc Res Update 1996; Issue 13 (Editor N. Gilbert), Guildford: University of Surrey. www.soc. surrey.ac.uk/sru/SRU13.htm

19. DeVries R., Benoit C, van Teijlingen E, Wrede S (eds.) Birth by Design: Pregnancy, Midwifery Care and Midwifery in North America and Europe, New York: Routledge, 2001.

20. Benoit C. The Politics of Health-Care Policy: The United States in Comparative Perspective. Perspect Biol Med 2003; 46 (4): 592-599.

21. Mander R. The relevance of the Dutch system of maternity care to the United Kingdom, J Advanc Nurs 1995; 22: 1023-1026.

22. Chambers R, Wakley G, Chambers S. Tackling Teenage Pregnancy: Sex, culture and needs. Abingdon: Radcliffe Medical Press, 2000

23. Nyman V. Going Dutch-A pipe dream? Crit J Fam Plann 1993; 19: 200-203.

24. De La Court A. Dutch surprise at British question Brit Med J 1995; 311: 1226.

25. Lewis, J, Knijn, T. A comparison of English and Dutch sex education in the classroom, Educ Health 2001; 19(4): 59-64.

26. DiCenso A, Guyatt G Willan A Griffith L. 2002. Interventions to reduce unintended pregnancies among adolescents: Systematic review of randomised controlled trials. Brit Med J 2002; 324: 1426

27. Keys D, Rosenthal D, Pitts M. Young people, sexual practice and meanings. In: Aggleton P, Ball A, Mane P. (eds.) Sex, Drugs and Young People: International Perspectives, London: Routledge, 2006, pp.120137

28. UNICEF, Child poverty in perspective: An overview of child wellbeing in rich countries, Innocenti Report Card 7, Florence: UNICEF Innocenti Research Centre, 2007.

29. OECD (Organisation of Economic Cooperation \& Development ) Organisation for Economic Co-operation and Development Doing Better for Children, OECD, 2009; www.oecd.org/els/social/childwellbeing

30. Office for National Statistics. Teenage pregnancies at record low: how does your local area compare? London, ONS, 2014, http:// www.ons.gov.uk/ons/rel/vsob1/conception-statistics--england-andwales/2012/sty-conception-rates.html

31. Poobalan AS, Pitchforth E, Imamura M, Tucker JS, Philip K, Spratt J, Mandava L, van Teijlingen E. Characteristics of effective interventions in improving young people's sexual health: A review of reviews Sex Educ 2009; 9 (3): 319-336.

32. Walker S, Palmer S, Sculpher M. The role of NICE technology appraisal in NHS rationing. Brit Med Bull 2007; 81(1): 51-64 